Int. J. Dev. Biol. 51: 201-209 (2007)

doi: $10.1387 / \mathrm{ijdb} .062176 \mathrm{qq}$

Original Article

\title{
Cell proliferation during the early compartmentalization of the Xenopus laevis inner ear
}

\author{
QUINCY A. QUICK ${ }^{1,2}$ and ELBA E. SERRANO ${ }^{1,3, *}$ \\ ${ }^{1}$ Department of Biology, New Mexico State University, Las Cruces, New Mexico, USA 2Department of Biology, Grambling State Univer- \\ sity, Louisiana, USA and ${ }^{3}$ Cell Decision Processes Center, Massachusetts Institute of Technology, Cambridge, Massachusetts, USA
}

\begin{abstract}
The auditory and vestibular endorgans of the inner ear which are essential for the senses of hearing and balance form early during development when the otocyst undergoes a period of rapid growth and compartmentalization. Here we show the spatial and temporal patterns of proliferating cells in the Xenopus laevis inner ear as this organ develops from an otic vesicle at stage 31 until stage 47, an age at which compartmentalization and the initial appearance of sensory structures are evident. Sites of new cell production were identified in specimens at stages $31,37,42,45$ and 47 using immunohistochemical methods to detect bromodeoxyuridine (BrdU) incorporation three hours after exposure to this thymidine analogue. Cells undergoing terminal mitosis at stages 37,42 and 45 were detected by exposing specimens at these stages to BrdU and permitting development to proceed until stage 47. Our results show that while newly replicating cells are uniformly distributed throughout the stage 31 otic vesicle, they are spatially restricted in stages 37 through 45, with few dividing cells visible in the central patches of the emerging sensory epithelia. In contrast, no clear proliferative pattern was discerned at stage 47. BrdU-positive cells that had undergone terminal mitosis at stage 37, 42 and 45 were detected in the central regions of nascent sensory epithelia at stage 47 . These findings are consistent with a developmental mechanism in which cells undergoing terminal mitosis during early $X$. laevis stages contribute to sensory epithelia and in which cell mixing and migration are features of inner ear compartmentalization.
\end{abstract}

KEY WORDS: inner ear, BrdU, otic vesicle, mitosis, Xenopus

\section{Introduction}

Hearing loss is an emerging global health problem with many underlying causes including genetic defects, noise, otoxic drugs, aging and disease (Arslan et al., 1999: Pellicer et al., 2005; Petit, 2006). The majority of hearing impairment is attributed to sensorineural hearing loss and is believed to arise from damage to the cells of the inner ear and of the neural pathways to the brain. Approximately 1 in 20 persons may suffer from sensorineural hearing loss, with vestibular dysfunction prevalent in many of these cases (Angeli, 2003; Mitchell, 2006). In humans, hearing loss is irreversible. This is partly due to the inability of the mammalian inner ear to recover proliferative capacity and regenerate its epithelial receptors, the mechanosensory hair cells, when these are damaged or destroyed (Chardin et al., 1995; Walsh et al., 2000; Matsui et al., 2005).

In contrast, it has been well established experimentally that other vertebrates such as birds (Stone and Cotanche, 1994;
Corwin and Oberholtzer, 1997), fish (Lombarte etal., 1993; Harris et al., 2003) and amphibians (Baird et al., 1993; Taylor and Forge, 2005) are capable of regenerating and replacing mechanosensory hair cells in individual endorgans of the inner ear in response to trauma or injury. Of special interest are findings from scanning electron microscopy studies of the amphibian inner ear that have shown the continued production of mechanosensory hair cells during development and adult life (Corwin, 1985; Kelley et al., 1992; Diaz et al., 1995; Serrano et al., 2001). Presently, the cellular mechanisms that govern proliferative development and regeneration are not clear, consequently requiring better characterization of mitotic processes and events in the inner ears of

Abbreviations used in this paper: ac, anterior canal; BrdU, bromodeoxyuridine; D, dorsal; hzc, horizontal canal; L, lateral; lag, lagena; ov, otic vesicle; pc, posterior canal; sac, sacculus; sg, sensory ganglion; utr, utricle; S31, stage 31; S37, stage 37; S42, stage 42; S45, stage 45; S47, stage 47; V, ventral; vz, ventricular zone; $\mathrm{X}$, Xenopus.

\footnotetext{
*Address correspondence to: Dr. Elba E. Serrano. Department of Biology, New Mexico State University, Las Cruces, New Mexico, 88003, USA. Fax: +1-505-646-5665. e-mail: serrano@nmsu.edu
} 
these different species. In particular, understanding of the proliferative events that occur early during the development of the nascent sensory epithelium may help to resolve open questions regarding the relative potential of supporting cells to convert to the hair cell phenotype through either mitotic or non-mitotic (transdifferentiation) mechanisms (Matsui and Ryals, 2005).

In the present study we examined mitotic activity during the early development of the Xenopus laevis (X. laevis) inner ear. The Xenopus inner ear originates from a placode that develops into a single compartment otic vesicle (otocyst) during embryonic life (Noramly and Grainger, 2002). Through complex morphogenic events that include invagination of the otic vesicle (Gallagher et al., 1996; Kil and Collazo, 2001), the otocyst gradually forms a multi-compartmentalized structure prior to metamorphosis. Resident within the mature inner ear are the eight sensory endorgans characteristic of anuran amphibians. Together, these organs serve as peripheral receptors for auditory (amphibian papilla; basilar papilla, sacculus) and vestibular (anterior, horizontal, posterior semicircular canals; utricle; lagena, sacculus) senses (Paterson, 1948; Nieuwkoop and Faber, 1967; Haddon and Lewis, 1991). In the amphibian inner ear, reception of sound of different frequencies is distributed among three endorgan structures that together accomplish the task of the single human cochlea. By mid larval life, well before metamorphosis, the Xenopus inner ear resembles the adult post-metamorphic form (Bever et al., 2003; Quick and Serrano, 2005).

This research was motivated by the expectation that a Xenopus experimental model would offer unique opportunities for investigating the regenerative potential of inner ear epithelia in an amphibian species where there is a strong anatomical and genetic foundation for mechanistic investigations (Kay and Peng, 1991; Amaya, 2005). To this end, we used bromodeoxyuridine (BrdU) incorporation to assess cell proliferation and terminal mitosis during the initial stages of compartmentalization of the Xenopus inner ear, a period when the sacculus (an acousticovestibular organ) and the vestibular organs first begin to appear (Paterson, 1948; Nieuwkoop and Faber, 1967; Bever et al., 2003; Quick and Serrano, 2005). BrdU incorporation previously has been implemented to identify mitotically dividing cells in endorgans of the undamaged inner ear (Wilkins etal., 1999; Lang etal., 2000) as well as the damaged inner ear (Stone and Cotanche, 1994; Zheng and Gao, 1997).

Cells undergoing replication were identified by transient exposure of $X$. laevis to BrdU during stages 31-47, a period where the inner ear is undergoing early compartmentalization as established in a prior study (Quick and Serrano, 2005). In one set of experiments, newly replicating cells in the inner ears of stages 31$47 X$. laevis were identified by immunohistochemical analysis three hours after BrdU exposure. In a second series of experiments, $X$. laevis were exposed transiently to BrdU at stages 3145 , then allowed to develop to stage 47 . At this stage, the initial formation of vestibular compartments is visible, as well as the presence of the mixed acoustico-vestibular organ, the sacculus. This second series of experiments permitted evaluation of the contribution of cells with earlier birthdates to the formation of stage 47 inner ear compartments.

The analysis of serial cryostat sections counterstained with hematoxylin revealed the temporal and spatial proliferative patterns produced by newly replicating cells within the otic epithelium and demonstrated extensive mitotic activity in the ventricular zone of the brain. BrdU-positive cells that had undergone terminal mitosis at stage 37,42 and 45 were detected in the sensory epithelia of the stage 47 sacculus and in other regions of the otic epithelium. Our results are in accordance with a developmental mechanism whereby cells that have undergone terminal mitosis during early $X$. laevis stages form part of the sensory epithelia of emerging sensory compartments and where cell mixing and migration characterize inner ear organogenesis.

\section{Results}

\section{Cell production in the $\mathrm{X}$. laevis otic vesicle during embry- onic (S31) and hatchling (S37, S42) stages}

Newly replicating cells were detected at S31 in all sections through the otic vesicle and in the ventricular zone of the brain (Fig. 1, A1-A4). Almost all cells in the S31 otic epithelium appear positive for BrdU. At this stage, there was an average of $152 \pm 41$ BrdU-positive cells (mean \pm S.D; $n=3$ ) in the otic vesicle (Table 1). Control sections that were processed without the primary antibody did not show immunoreactivity to the secondary antibody at this stage (Fig. 1A5), nor at any other stage.

BrdU-positive cells also were present in all sections through the S37 otic vesicle. However in middle sections of the S37 otic vesicle a spatial pattern of cell production becomes apparent. BrdU-positive cells were few or absent from the thickened central zone of the ventromedial otic epithelium (Fig.1, B1-B3), the region where the saccular epithelium emerges (Corwin, 1985; Quick and Serrano, 2005). As observed at S31, BrdUpositive cells were present in the ventricular zone of the S37 brain (Fig. 1B4). Additionally, we observed cell replication in the S37sensory ganglion (Fig. 1B2). Counts through the entire inner ear of one S37 specimen yielded an estimated mitotic index of $78 \%$ for the otic epithelium. There was an average of $431 \pm 128$ (mean \pm S.D; $n=3$ ) BrdU-positive cells in the S37 otic epithelium (Table 1), an increase of $184 \%(p<0.07)$ as compared with the average number of BrdU-positive cells observed at S31.

Mitotic cell production was detected in the entire otic vesicle and in the ventricular zone of the brain of S42 specimens (Fig. 1, C1-C4). The emerging spatial pattern of mitotic cells visible at S37 was more pronounced at S42. As in S37, few BrdUpositive cells were detected in middle sections of the inner ear in the thickened central zone of the ventromedial otic epithelium. Actively replicating cells were detected in the lateral

TABLE 1

\section{CELL PRODUCTION IN THE $X$. LAEVIS OTIC EPITHELIUM} DURING INNER EAR DEVELOPMENT

\begin{tabular}{lcccc} 
S31 & S37 & S42 & S45 & S47 \\
\hline 106 & 474 & 418 & 862 & 504 \\
164 & 287 & 388 & 673 & 881 \\
185 & 533 & 478 & 821 & 805 \\
\hline $152 \pm 41$ & $431 \pm 128$ & $428 \pm 46$ & $785 \pm 99$ & $730 \pm 199$
\end{tabular}

BrdU-positive cells were counted in sections through the entire inner ear of three animals at each animal age. Single factor ANOVA analysis showed a statistically significant increase $(p<0.001$; $\mathrm{F}=14.2$ ) in the number of BrdU positive cells between stages $31,37,42,45$ and 47 during $X$. laevis otic vesicle development (mean \pm standard deviation; $n=3$ ) 

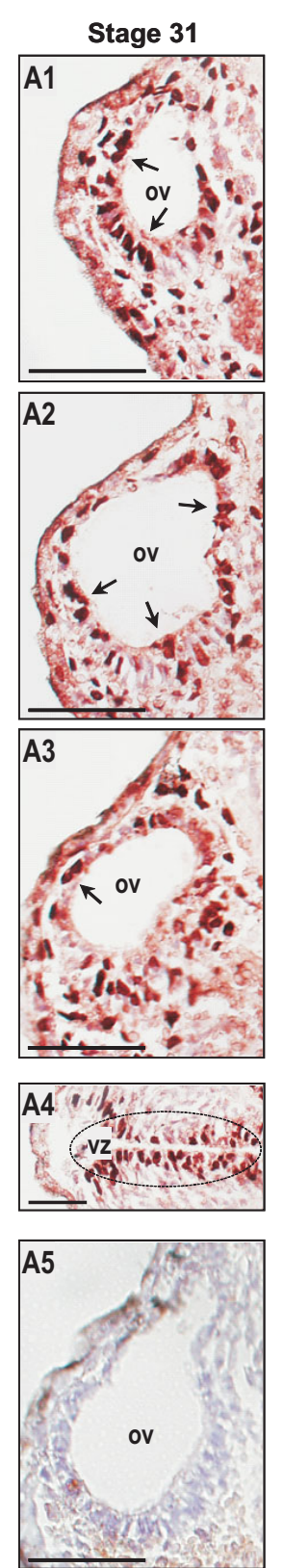

NovaRed(BrdU)
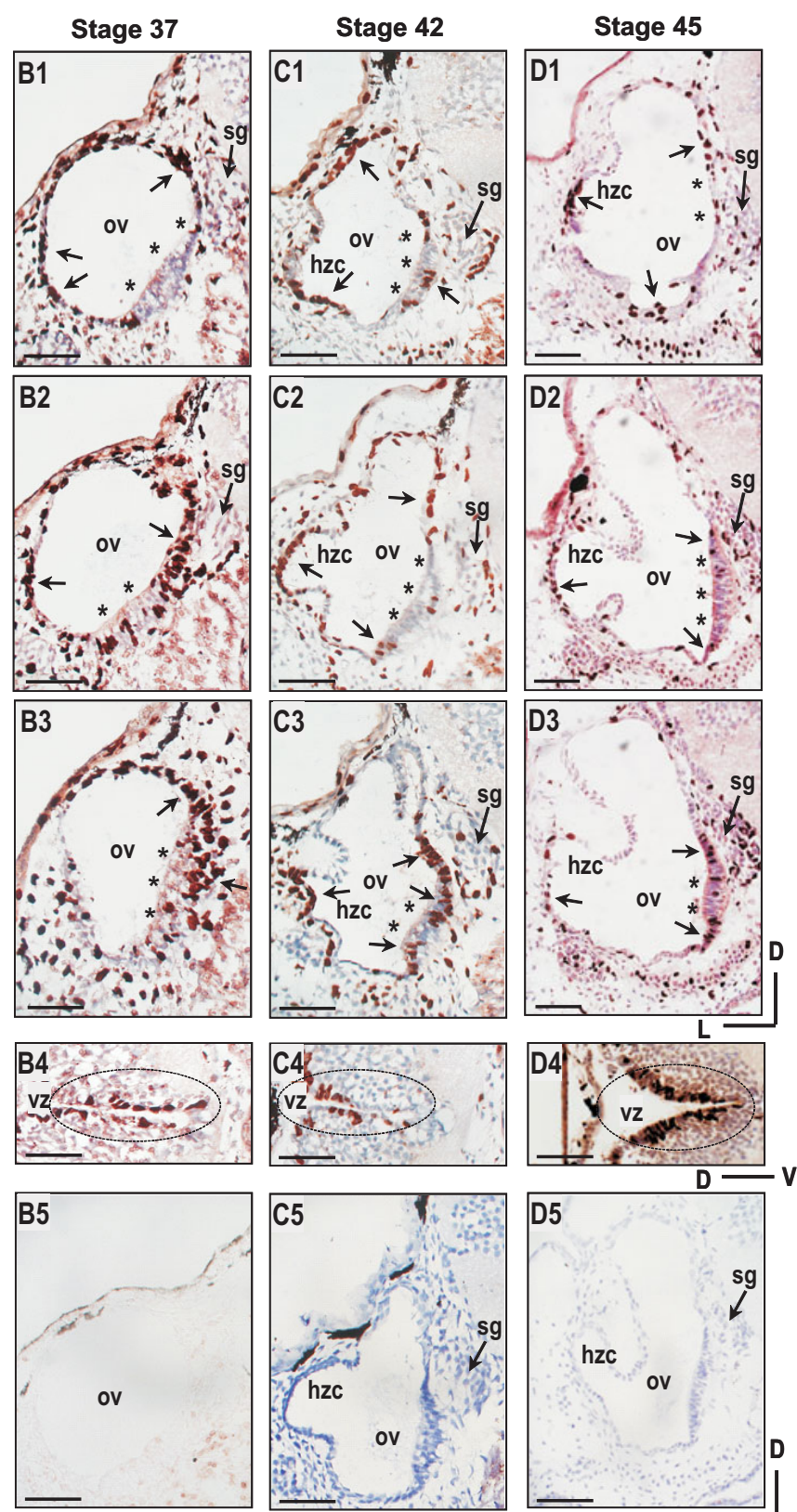

Hematoxylin

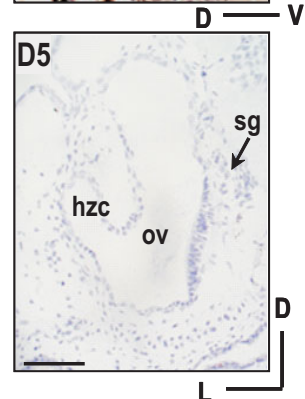

Fig. 1. Cell proliferation in the stage 31 (A), 37 (B), 42 (C) and 45 (D) X. laevis inner ear, three hours after transient exposure to BrdU. Representative anterior to posterior sections (A1-A3; B1-B3; C1-C3; D1-D3) show BrdU-positive cells labelled with anti-BrdU antibody (red/brown; arrows) and counterstained with hematoxylin (blue/violet). (A) At stage 31, BrdU-positive cells are distributed throughout the epithelium of the otic vesicle (A1-A3). (B-D) Few BrdU-positive cells are detected in the emerging saccular epithelium (asterisks), while BrdU-positive cells can be seen flanking these regions in the stage 37 (B1-B3), 42 (C1-C3) and 45 (D1-D3) inner ear. BrdU-positive cells (arrows) can be seen restricted to other regions of the otic epithelium and within the sensory ganglion at stage 42 (C1-C3) and 45 (D1-D3). BrdU-positive cells (dashed circles) are visible in the ventricular zone of the brain in all stages $(A 4, B 4, C 4, D 4)$. Control sections processed for immunohistochemistry with secondary antibody but without primary (anti-BrdU) antibody and counterstained with hematoxylin (blue/violet) are shown in panels A5, C5, D5; panel B5 shows a control section that was not counterstained with hematoxylin. Scale bar, $100 \mu \mathrm{m}$.

region of the S42 otic vesicle and were especially predominant between the budding axial protrusions that will extend and eventually fuse to form the walls of the horizontal semicircular canal (Haddon and Lewis, 1991). Counts from one specimen yielded an estimated mitotic index of $65 \%$ for the S42 otic vesicle and an average of $428 \pm 46$ (mean \pm S.D; $n=3$ ) BrdUpositive cells present at this stage (Table 1).

\section{Cell production in the $\mathrm{X}$. laevis inner ear during early larval stages (S45, S47)}

At S45 the spatial patterns established by BrdU-positive cells resemble those seen at S42. Although replicating cells can be seen in sections throughout the entire otic vesicle and the ventricular zone of the brain, few BrdUpositive cells are visible in the central region of the emerging saccular zone and in the axial protrusions of the horizontal canal (Fig. 1, D1D4). A mitotic index of $61 \%$ was estimated for the S45 otic vesicle based on counts from one specimen. There is a significant increase of $83 \%$ in the average number of BrdU-positive cells $(785 \pm 99 ;$ mean \pm S.D; $n=3)$ present in the S45 otic epithelium (Table 1) as compared with those detected at $S 42(p<0.02)$.

We previously have demonstrated with histological sectioning and confocal microscopy that by S47 the initial formation of the endorgan compartments that contain the sensory epithelia for vestibular (utricle, lagena, canals) and acoustico-vestibular (sacculus) sense reception is evident (Quick and Serrano, 2005). In sections from S47 specimens, we did not discern distinct spatial patterns of BrdU-positive cells in the otic epithelium (Fig. 2, A-D). Anterior sections of the $S 47$ inner ear revealed BrdU-positive cells in dorsal and lateral regions of the utricle (Fig. 2A, B) and in the endorgan compartments of the sacculus, horizontal canal and anterior canal (Fig. 2B). In middle sections of the S47 inner ear, cell production was observed throughout the emerging saccular epithelium (Fig. 2C), while posterior sections showed the presence of BrdU-positive cells in the otic epithelium of the nascent lagena and posterior canal (Fig. 2D). There was an average of $730 \pm 199$ (mean \pm S.D; $n=3)$ BrdU-positive cells in the S47 inner ear (Table 1). A mitotic index of $39 \%$ was estimated for this stage for one specimen. As seen in earlier $X$. laevisotic vesicle stages, BrdU-positive cells also were visible at S47 in the sensory ganglion and ventricular zone of the brain (Fig. 2C, E). S47 was the oldest stage where the BrdU immersion method was a reliable procedure for identifying dividing cells as confirmed by $100 \%$ animal survival, the timing of developmental 


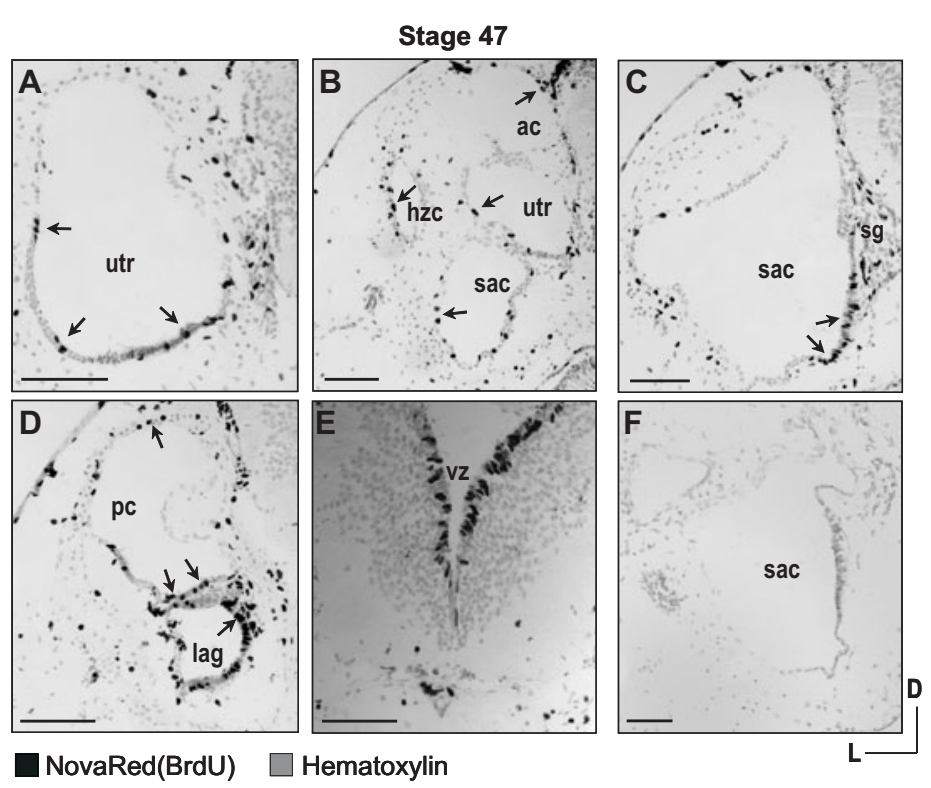

Fig. 2 (Left). Cell proliferation in nascent sensory compartments of the stage $47 X$. laevis inner ear, three hours after transient exposure to BrdU. Anterior to posterior sections representing the entire inner ear ( $A-D$ ) show the presence of BrdU-positive cells (deep black; arrows) in the epithelia of all endorgan compartments. (A) BrdUpositive cells are more prevalent in the ventral regions of the utricle in anterior sections. (B) BrdU-positive cells are distributed throughout the epithelium of the utricle, horizontal canal, sacculus and anterior canal. (C) BrdU incorporation was detected in the saccular sensory epithelium and in the sensory ganglion. (D) BrdU-positive cells are visible in the lagena and posterior canal in posterior sections of the inner ear. (E) BrdU-positive cells were detected in the ventricular zone of the brain. (F) Control section processed for immunohistochemistry with secondary antibody but without primary (anti-BrdU) antibody. Hematoxylin counterstain (grey). Scale bar, $100 \mu \mathrm{m}$.

Fig. 3 (Right). Terminal mitosis in the inner ear of stage $47 X$. laevis that were transiently exposed to BrdU at stages 37 (A), 42 (B) and 45 (C). Anterior to posterior sections representing the entire inner ear show the presence of BrdU-positive cells (black/dark-grey) with birthdates from earlier stages (S37, A1-A3; S42, B1-B3; S45, C1-C3) in stage 47 otic epithelia. Cells that had undergone terminal mitosis (arrows, dashed circles) are predominantly seen in the central regions of the emerging sensory epithelia of the utricle (A1, B1, C1) and of the sacculus (A2-A3, B2-B3, C2-C3) regardless of stage of BrdU exposure. Images of the saccular region within the dashed circles are shown at higher magnification underneath the corresponding panels. Control sections processed for immunohistochemistry with secondary antibody but without primary (anti-BrdU) antibody and counterstained with hematoxylin are shown in panels (A4, B4, C4) for the saccular epithelium. Hematoxylin counterstain (light grey). Scale bar, 50 um.

progression as compared with controls and the labeling of cells of the ventricular zone.

\section{Terminal mitosis in the newly compartmentalized X. laevis inner ear (S47)}

The cessation of mitotic activity through terminal mitosis was evaluated during inner ear organogenesis by exposing $X$. laevis at S37, S42 and S45 to BrdU and then permitting development to proceed to S47 (Fig.3, Fig. 4B). Similar spatial patterns of BrdUpositive cells were observed in S47 sections, irrespective of the stage at which animals were exposed to BrdU. In anterior sec-
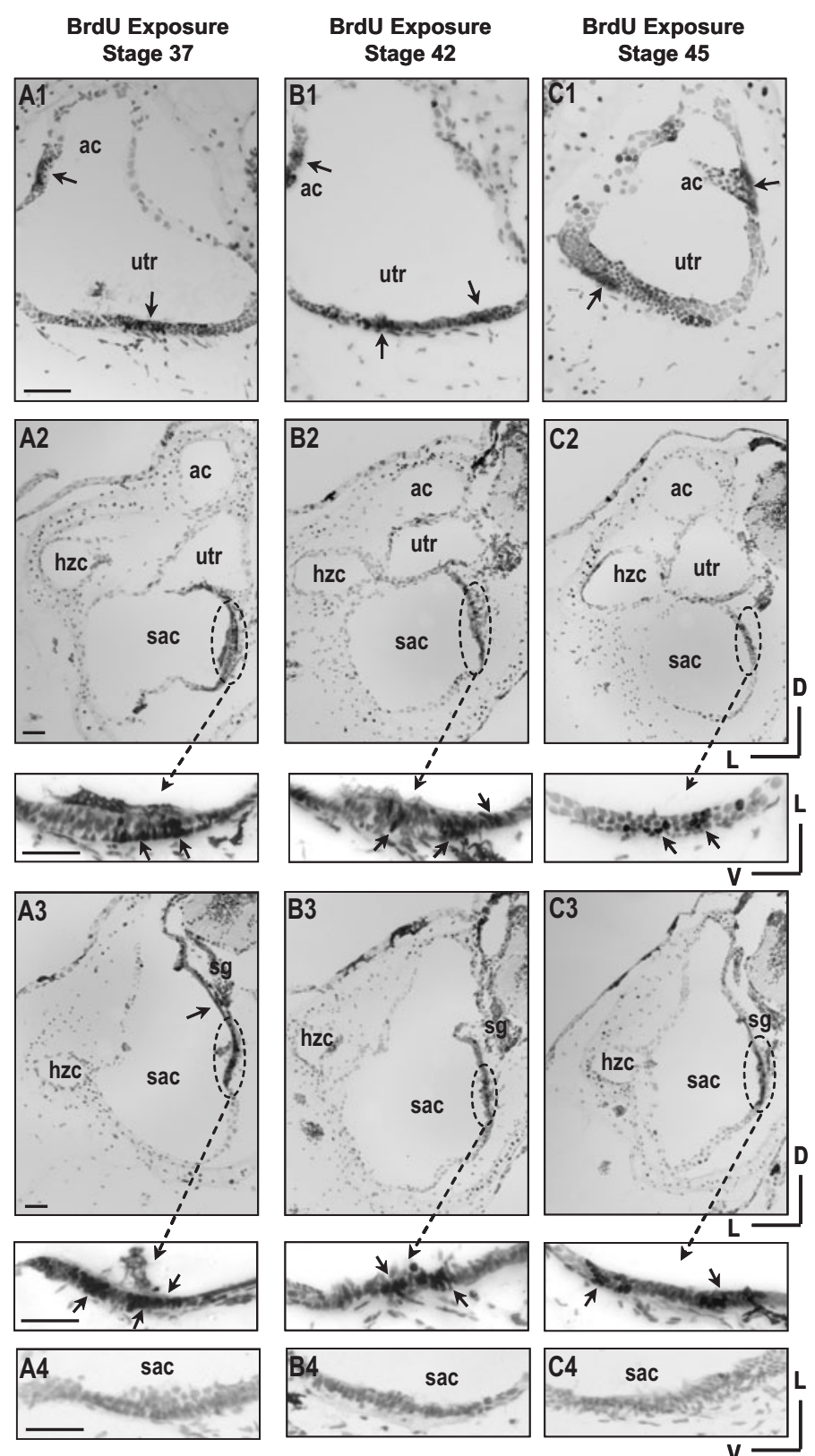

NovaRed(BrdU) $\square$ Hematoxylin tions, BrdU-positive cells were visible in the ventral and lateral portion of the utricle (Fig. 3A1, B1, C1) and in endorgan compartments of the horizontal canal, anterior canal and sacculus (Fig. 3A2, B2, C2). Sections through the inner ear showed BrdUpositive cells that had undergone terminal division at earlier stages located within the central zone of the saccular epithelium (Fig. 3A3, B3, C3).

In Fig. 4, the spatial patterns established by newly replicating cells in the emerging saccular region of the otic epithelium of S37 (Fig. 4A1), S42 (Fig. 4A2) and S45 (Fig. 4A3) specimens are compared with those visible in the saccular epithelium of S47 $X$. 
laevis that had been exposed to BrdU at S37 (Fig. 4B1), S42 (Fig. 4B2) and $S 45$ (Fig. 4B3). As can be seen in Fig. 4, newly replicating cells were visible primarily in the periphery of the emerging saccular epithelium (Fig 4A). In contrast, by S47, cells with earlier birthdates could be seen distributed throughout the central zone of the saccular epithelium (Fig. 4B).

\section{Discussion}

Here we have demonstrated the presence of continued cell production during early $X$. laevisinner ear organogenesis. Analysis of our data revealed a steady increase in the total number of BrdU-positive cells that were detected in cryosectioned tissue as the $X$. laevis inner ear developed from a single compartment otic vesicle at S31, into a multi-compartmentalized structure by S47 (Table 1). However BrdU-positive cells can be seen to comprise progressively less of the otic epithelium as development proceeds (Fig. 1, 2) and estimates for mitotic index declined from $78 \%$ at S37 to $39 \%$ at S47. Previous morphological studies based on paint-filled ears and histological serial sections have estimated
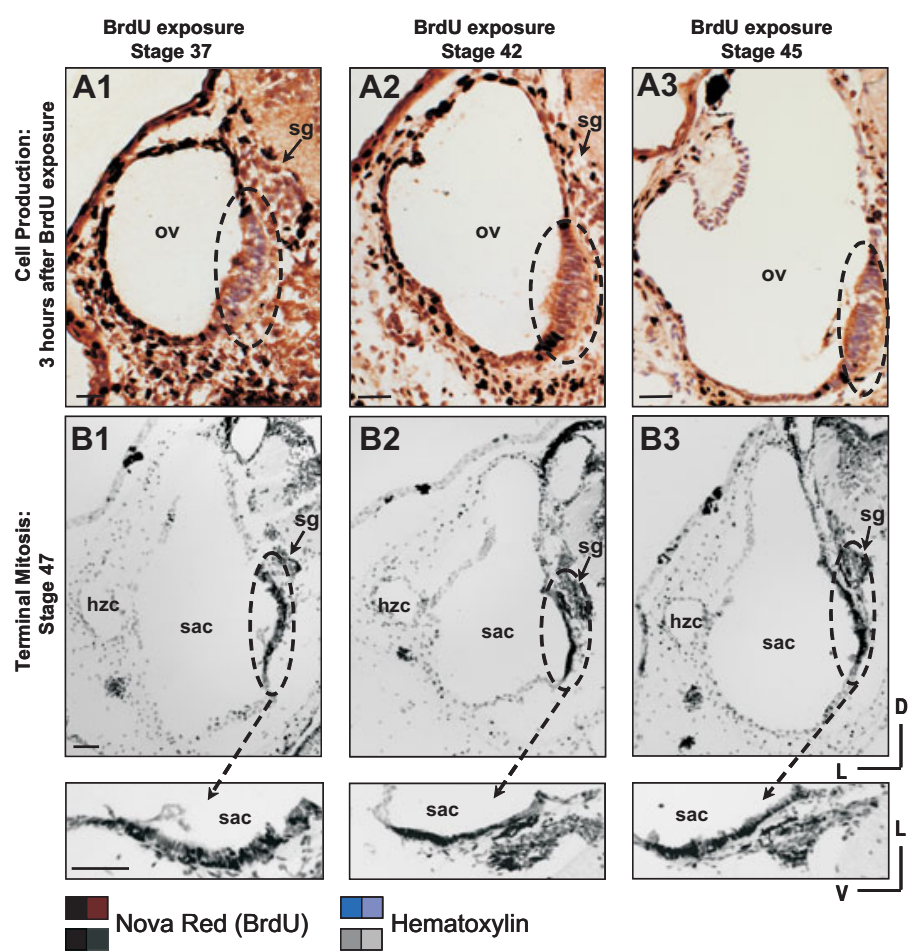

that the $X$. laevis inner ear increases approximately six fold in the anteroposterior dimension during this period (Bever et al., 2003; Quick and Serrano, 2005). Our findings suggest that inner ear growth is correlated with high levels of cell production relative to the total number of cells in the otic epithelium in the early stages of compartmentalization and that dividing cells comprise proportionately less of the otic epithelium as the sensory endorgans and compartments of the inner ear emerge (Table 1, Figs. 1, 2, 4A, 5).

A distinct spatial proliferative pattern was first observed at S37 (Fig. 1, B1-B3; Fig. 5B). At this stage, few or no BrdU-positive cells were detected within the central zone of the emerging saccular epithelium, while newly replicating cells were visible at the outer margins of this region of thickened epithelium and occasionally in the underlying supporting cell layer. A similar spatial pattern also was observed in the otic vesicle at S42 (Fig. 1, C1-C3; Fig. 5C) and S45 (Fig. 1, D1-D3; Fig. 5D). Actively dividing cells also were visible in the sensory ganglion of the developing $X$. laevis otic vesicle as early as S37 and in all later stages. Nerve growth factor (Represa and Bernd, 1989) and transforming growth factor $\beta 2$ (Okano et al., 2005) have been implicated in sensory ganglion
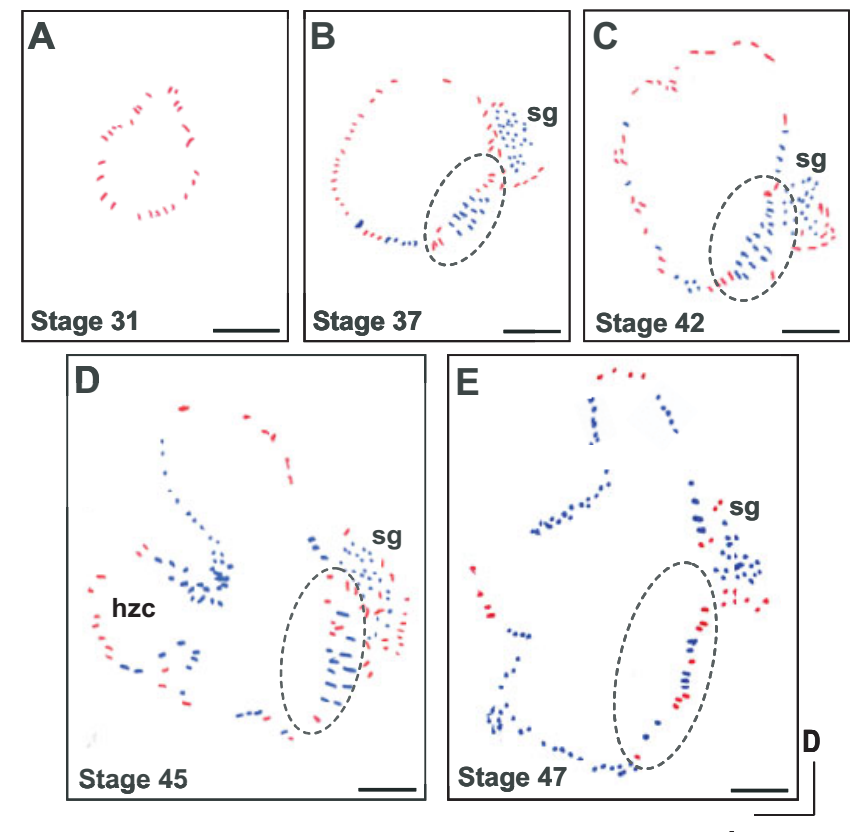

NovaRed (BrdU)

Hematoxylin

$\mathbf{L}$

Fig. 4 (Left). Comparison of new cell production (A) and terminal mitosis (B) in the saccular region of the $X$. laevis inner ear. (A) Cell proliferation observed after three hours of development following transient BrdU exposure at stages 37 (A1), 42 (A2) and 45 (A3). BrdU-positive cells (red/brown) flank the emerging saccular epithelium (dashed circles) at all stages. Few BrdU-positive cells are detected within the thickened region of the saccular epithelium. (B) Terminal mitosis observed at stage 47 following BrdU exposure at stage 37 (B1), 42 (B2) and 45 (B3). Images of the saccular region within the dashed circles are shown at higher magnification underneath the corresponding panels. In contrast to Fig. 4A, BrdU-positive cells (black) dark-grey) with birthdates from earlier stages are prevalent in the thickened central region of the saccular epithelium (dashed circle). Hematoxylin counterstain (A, blue/violet; $B$, light grey). Scale bar, $50 \mu \mathrm{m}$.

Fig. 5 (Right). Schematic diagrams illustrating cell production in sections of the stage 31 (A), 37 (B), 42 (C), 45 (D) and 47 (E) X. laevis inner ear that contain saccular epithelium (dashed circles) and the sensory ganglion (sg). (A) At early stages, BrdU-positive cells (red) are distributed throughout the entire epithelium of the stage 31 otic vesicle. (B-D) At stages 37 (A), 42 (B) and 45 (C), BrdU-positive cells are detected throughout the otic epithelium but appear restricted to specific regions such as the outer boundaries of the emerging saccular sensory epithelium and flanking the protrusions of the emerging horizontal canals (D). (E) In the stage 47 inner ear, BrdU-positive cells are distributed throughout the otic epithelium without a distinct trend toward localization in a particular region. Hematoxylin counterstain (blue). Scale bar, $100 \mu \mathrm{m}$. 
cell production during early otic vesicle development in quail and mouse respectively. It is possible that these or other neurotrophic factors may be stimulating mitosis of sensory neurons at these early developmental stages in $X$. laevis.

In Xenopus, as in other amphibians, the sensory epithelium of the acoustico-vestibular sacculus is the first sensory epithelium that can be distinguished during development. The saccular epithelium of amphibians comprises a circular central patch populated by mechanosensory hair cells with actin-rich sterociliary bundles interspersed among supporting cells ( $\mathrm{Li}$ and Lewis, 1979; Corwin 1985; Diaz et al., 1995). The presence of hair cell bundles within the thickened $X$. laevis saccular primordia (Figs. 1-4) has been confirmed previously using fluorescent phalloidin probes to label F-actin in histological sections of the inner ear at animal stages identical to those used in this study (Quick and Serrano, 2005). Moreover, the postembryonic emergence of hair cell bundles at the outer margins of the X. laevis (Diaz et al., 1995), Rana catesbeiana (Li and Lewis, 1979) and Bufo marinus saccular epithelium (Corwin 1985) has been demonstrated with scanning electron microscopy. Additionally, Corwin (1985) has shown that when $B$. marinus are exposed to tritiated thymidine, hair cells at the outer margins of the sacculus appear radioactively labeled in sectioned tissue. Taken together with our results from cell production studies, these findings are consistent with a mechanism where production of new hair cells is coupled to mitotic events that are enriched at the margins of the growing saccular sensory epithelium during early organogenesis (Fig. 5).

We further noted that newly replicating cells were rarely seen in the epithelium of the paired outpocketings that eventually will fuse to form the walls of the horizontal canal in S42 (Fig. 1, C1C3) and S45 (Fig. 1, D1-D3) X. laevis. However, BrdU-positive cells were prevalent in the region between the two axial protrusions at these stages. Based on experimental evidence, Haddon and Lewis (1991) have proposed a mechanism for semicircular canal formation whereby localized synthesis of hyaluronan into the core of the outpocketings, by epithelial cells at the tip of the protrusions, drives the extension of the outpocketings into the lumen of the $X$. laevis otocyst. The spatial pattern of BrdUpositive cells in the regions where the horizontal canal is forming suggests that new cells are preferentially added by cell division to the base of the axial protrusions during early semicircular canal formation.

In contrast to earlier stages, no clear spatial pattern of new cell production was discerned at S47, a stage where compartmentalization and endorgan formation are accelerated (Fig. 2). The absence of distinct proliferative patterns in the S47 inner ear potentially can be attributed to the dramatic morphological changes that occur between S45 and S47. Between these two stages, a gap of approximately 72 hours, the inner ear doubles in size in the anteroposterior dimensions (Bever et al., 2003; Quick and Serrano, 2005). Invaginations required for compartment formation are predominant during this period of development (Paterson, 1948; Haddon and Lewis, 1991; Quick and Serrano, 2005) and may disrupt spatial patterns established during earlier otic vesicle stages (Torres and Giraldez, 1998). The widespread distribution of BrdU-positive cells throughout the otic epithelium of S47 specimens also is consistent with a developmental mechanism where newly replicating cells mi- grate from other regions to pattern sensory epithelia and contribute to endorgan formation and enlargement of the inner ear (Goodyear and Richardson, 1997; Kil and Collazo, 2001; Bianchi et al., 2006).

Terminal mitosis experiments from the present study revealed that cells that ceased to proliferate during $X$. laevis otic vesicle development were predominantly localized to central regions of the $S 47$ saccular epithelium and utricle regardless of the stage of BrdU exposure (Fig. 3; Fig. 4B). As in the cell production studies, BrdU-positive cells could be detected in the supporting cell layer that underlies the central sensory zones. Our attempts to visualize hair cell bundles within the central zone by co-labeling sections from specimens exposed to BrdU with fluorescent phalloidin as per a previous anatomical study of early inner ear organogenesis (Quick and Serrano, 2005) were unsuccessful. We attribute this difficulty to the requirement for hydrochloric acid treatment as part of the BrdU labeling protocol. This procedure is necessary to denature the labeled DNA and is known to degrade proteins and compromise immunodetection protocols. However, the identity of the cells that have terminally divided in the central region of the saccular and utricular epithelium can be inferred from previous histological investigations of hair cells and supporting cells in $X$. laevis S47 inner ears (Diaz et al., 1995; Quick and Serrano, 2005) as well as results from other studies of the amphibian sacculus and utricle (Li and Lewis, 1979; Corwin, 1985).

Our results from terminal mitosis studies suggest that precursor cells that divide in the presence of BrdU at earlier stages are able to generate new hair cells and supporting cells for the central sensory zone of the S47 saccular and utricular epithelium (Fig. 3, Fig. 4B). However, although terminal mitosis experiments show that BrdU-positive cells with birthdates from earlier stages are confined principally to central regions of the sensory patches of the S47 inner ear (Fig. 3, 4B), cell production studies show that newly replicating cells are distributed throughout the S47 otic epithelium in no obvious pattern (Fig. 2 ). These findings underscore the complexity of inner ear development and raise questions about underlying mechanisms, such as the contribution of apoptotic events to development of the $X$. laevis inner ear and the observed patterns of cell proliferation. In chick, there is evidence that a complex interplay between apoptosis and cell proliferation contributes to the initial development of the embryonic otocyst and that regional otic outgrowth does not necessarily correlate with high cell proliferation (Lang et al., 2000). Analysis of TUNEL-stained Xenopus whole mounts from stages 10 to 36 has shown that programmed cell death is prevalent during early Xenopus development and is especially heightened in neural tissue and sensory organs between stages 26 to 35 (Hensey and Gautier, 1998). Therefore, it is plausible that mitotic patterns observed in this study are the net result of processes that control cell proliferation and programmed cell death during inner ear development.

Based on a substantial body of research, two main mechanisms have been proposed for sensory hair cell regeneration following damage or trauma (Matsui and Ryals, 2005). In one model, new hair cells arise from the non-mitotic phenotypic conversion, or transdifferentiation, of supporting cells into hair cells. In the other model, new hair cells are thought to arise 
following mitosis of supporting cells and the subsequent differentiation of daughter cells into two hair cells, or a hair cell and a supporting cell. The intriguing observation that BrdU-positive cells could be detected in the supporting cell layer underlying the central sensory zone in both the cell production (Fig. 1B2-B3, C23, D2-3) and the terminal mitosis studies (Fig. 3, Fig. 4) may signify a potential role for these cells as hair cell progenitors during early inner ear development through a process that requires mitosis and differentiation.

Although BrdU incorporation is a popular and established method for identifying newly replicating cells (Gratzner, 1982; Miller and Nowakowski, 1988; Stone and Cotanche, 1994; Lang et al., 2000), it is known that BrdU can affect normal development and morphology if it is delivered in certain dosage regimens and for long exposure times (Stockdale et al., 1964; Kolb et al., 1999; Pizarro et al., 2004). In this study we minimized deleterious effects of BrdU by optimizing our protocols and with our methods, BrdU administration resulted in zero mortality among experimental animals. Moreover, the implementation of an immersion method comparable to what previously has been used with larval zebrafish (Kimmel et al., 1998) reduced the stress that is associated with administration by invasive injection methods. The limitation of the immersion method is that beyond a certain animal size (S47), immersion is not an effective means for BrdU delivery to the otic vesicle. In our experiments, the efficacy of BrdU administration by im'mersion was confirmed in all specimens in this study through the presence of BrdU-positive cells in the ventricular zone of the brain (Chapman et al., 2006).

In summary, the limited capability of the mammalian inner ear to regenerate damaged sensory cells in response to insult or injury due to terminal cell division during development is well characterized (Chardin et al., 1995; Walsh et al., 2000; Matsui et al., 2005). Amphibians such as Xenopus offer an alternative model for unraveling mechanisms that promote regeneration in an organism that is well characterized genetically and developmentally (Nieuwkoop and Faber, 1967; Amaya, 2005). Furthermore, the increasing interest in the use of amphibians such as Xenopus to investigate cell proliferation during development of the olfactory bulb (Fritz et al., 1996), the spinal cord (Schlosser et al., 2002) and the auditory medulla (Chapman et al., 2006), will provide a foundation for comparative studies of the regenerative potential of amphibian neural and sensory tissue as compared with that of other vertebrates. Here we have demonstrated the spatial and temporal patterns that characterize cell proliferation in the developing $X$. laevisinner ear during the period leading to the initial compartmentalization of auditory and vestibular structures at S47, as well as the contribution of cells that had undergone terminal mitosis during earlier stages to the formation of the emerging S47 sensory epithelia. Results are in agreement with models for inner ear development that identify the marginal regions of sensory epithelia as hot spots for cell proliferation ( $\mathrm{Li}$ and Lewis, 1979; Corwin, 1985; Diaz et al., 1995; Serrano et al., 2001). Our findings also are consistent with those of Kil and Collazo (2001), whose cell lineage analysis demonstrated that cells from different regions of the otocyst can contribute to sensory organ formation and that inner ear development is characterized by cell mixing. Identification of the mechanisms that promote proliferation in the developing amphibian inner ear may prove significant in defining strategies that will restore the ability of the mammalian inner ear to recover proliferative capacity in response to damage (Matsui and Ryals, 2005; Pellicer et al., 2005).

\section{Materials and Methods}

\section{Xenopus laevis and bromodeoxyuridine administration}

$X$. laevis were purchased from a commercial supplier (NASCO, Fort Atkinson, WI), staged under a dissecting microscope according to the Nieuwkoop and Faber table for $X$. laevis development (Nieuwkoop and Faber, 1967) and classified as embryonic (stage 31), hatchling (stage 37 , stage 42) and early larval (stage 45, stage 47) as per McDiarmid and Altig (1999). The stages used for the present study were selected according to the morphological changes that occur during early inner ear compartmentalization (Quick and Serrano, 2005). BrdU (Sigma B9285) was administered to stage $31,37,42$ and $45 X$. laevis by immersion in $10 \mathrm{mM}$ BrdU in phosphate buffered saline (PBS; Sigma-Aldrich P3813) for thirty minutes at room temperature $\left(22-26^{\circ} \mathrm{C}\right)$ as described by Kimmel et al. (1998); stage 47 specimens were immersed in $20 \mathrm{mM} \mathrm{BrdU} \mathrm{in} \mathrm{PBS} \mathrm{for} \mathrm{one}$ hour. For cell production studies of newly replicating cells, X. laeviswere allowed to develop for three hours after BrdU exposure prior to euthanasia; for terminal mitosis studies of cell birthdates, animals were allowed to develop to stage 47 (approximately 15 days). In the terminal mitosis experiments, BrdU uptake was confirmed by allowing a set of animals from each stage $(37,42,45)$ to develop for three hours and processing tissue for BrdU incorporation using immunohistochemical methods. At the end of the experimental developmental period, animals were euthanized in $0.25 \%$ buffered $(\mathrm{pH} 7.4)$ 3-aminobenzoic acid ethyl ester methanesulfonate salt (Tricaine; Sigma A-5040). Treatment regimens were optimized such that our protocols resulted in zero mortality for experimental and control animals. Experimental procedures were approved by the Institutional Animal Care and Use Committee of New Mexico State University.

\section{Immunohistochemistry}

After euthanasia, animals were fixed in 4\% p-formaldehyde/PBS for 2 hours at room temperature, rinsed with PBS, embedded in $5 \%$ sucrose/ $5 \%$ agar and cryoprotected overnight at $4{ }^{\circ} \mathrm{C}$ in $30 \%$ sucrose $/ 0.1 \%$ sodium azide in PBS. Slides were prepared using tissue that was sectioned to 15 $\mu \mathrm{m}$ on a Leica 3050 cryotome. Sections were incubated for 30 minutes at $37^{\circ} \mathrm{C}$ with $2 \mathrm{~N} \mathrm{HCl}$ in $\mathrm{PBS} / 0.1 \%$ Triton- $\mathrm{X} 100$ to denature DNA strands, rinsed in PBS, then treated with $0.5 \% \mathrm{H}_{2} \mathrm{O}_{2}$ in methanol for 15 minutes and rinsed with PBS (2X, 5 min.). The VectaStain Elite ABC Kit (Vector Labs, PK-6102) was used to immunolabel the mouse monoclonal anti-BrdU primary antibody (1:300; Sigma B2531) with a biotinylated secondary antibody and an Avidin:Biotinylated enzyme Complex (ABC) by optimizing the protocol as per the manufacturer's recommendations.

Slides were processed for color detection according to the manufacturer's protocol using a peroxidase substrate method (Vector Labs NovaRed Substrate Kit SK-4800), then counterstained with Harris hematoxylin (Sigma HHS-16). Sections were dehydrated in 50\%, 75\%, $100 \% \mathrm{EtOH}$ and coverslipped with Histomount. Two sets of control sections were studied in parallel with animals treated with BrdU and processed with the primary (anti-BrdU) and secondary antibodies. Nonspecific binding of the secondary antibody was evaluated in control sections from specimens that were exposed to BrdU and were not processed with the primary antibody. Non-specific binding of the primary antibody was evaluated in control sections from specimens that were not exposed to BrdU but were processed for immunohistochemistry with primary and with secondary antibody.

\section{Data analysis}

Images of sectioned tissue were digitally captured using a Zeiss Axioplan microscope and image acquisition system (Pixera, Princeton 
Instruments; Qimage, Olympus). The digitized images were processed in AdobePhotoshop for figure preparation. Sections presented in figures are representative of at least three independent experiments performed that included three animals per experiment per stage. Counts of BrdU-positive and hematoxylin-labeled cells in the otic epithelium were obtained for three independent experiments from tracings of digitized images projected on a computer monitor. Mitotic indices were estimated at each stage using one set of sections by counting the number of BrdU positive cells and the number of total cells (BrdU-positive plus hematoxylinlabeled cells) in the otic epithelium in sections through the entire inner ear. The mitotic index for the whole otic epithelium was calculated by dividing the number of BrdU-positive cells by the total number of cells counted. In the cell production study, a single factor analysis of variance test (ANOVA) was used to compare the mean number of BrdU-positive cells between all five stages (Table 1). The level of significant difference between the mean number of BrdU-positive cells detected in successive stages (e.g. 31 and 37) was established with Student's t-test.

\section{Acknowledgements}

We are grateful to Drs. Graciela Unguez and Jennifer Lucitti for technical advice regarding experimental procedures, to Dr. TuShun Powers, Ms. V. Bleu Knight, Ms. Marti Morales and Mr. David Sultemeier for critical reading of the manuscript and to Ms. Casilda Trujillo-Provencio for assistance with figure preparation. Funding for this research was provided by awards to EES from NIH NIGMS SCORE (3SO6GM08136), NIDCD DC003292, NASA (NAG2-1334) and the MIT Cell Decision Processes Center (NIH P50GM068762). QAQ received support from an NIH NIGMS RISE training grant (GM 61222-02), a NASA New Mexico Space Grant Consortium Fellowship (NGT 40087) and the NMSU College of Arts and Sciences.

\section{References}

AMAYA E. (2005). Xenomics. Genome Res. 15: 1683-1691.

ANGELI, S. (2003). Value of vestibular testing in young children with sensorineural hearing loss. Arch. Otolaryngol. Head Neck Surg. 129: 478-482.

ARSLAN E, ORZAN E. AND SANTARELLI R. (1999). Global problem of druginduced hearing loss. Ann. NY Acad. Sci. 884:1-14.

BAIRD, R.A., TORRES, M.A. AND SCHUFF, N.R. (1993). Hair cell regeneration in the bullfrog vestibular otolith organs following aminoglycoside toxicity. Hear. Res. 65: 164-74.

BEVER M.M., JEAN Y.Y AND FEKETE D.M. (2003). Three-dimensional morphology of inner ear development in Xenopus laevis. Dev. Dyn. 227: 422-430.

BIANCHI L.M., HURI D. AND WHITE I.O. (2006). Embryonic inner ear cells use migratory mechanisms to establish cell patterns in vitro. J. Neurosci. Res. 83:191-8.

CHAPMAN J.A., WEINSTEIN J.L. AND SIMMONS A.M. (2006). Cell proliferation in the Rana catesbeiana auditory medulla over metamorphic development. $J$. Neurobiol. 66: 115-133.

CHARDIN, S., ROMAND, R., LEFEBVRE, P. AND MALGRANGE, B. (1995) Regeneration and mammalian auditory hair cells. Science 267: 707-713.

CORWIN, J.T. (1985). Perpetual production of hair cells and maturational changes in hair cell ultrastructure accompany postembryonic growth in amphibian ear. Proc. Natl. Acad. Sci. USA 82: 3911-3915

CORWIN, J.T. and OBERHOLTZER, J.C. (1997). Fish n' chicks: model recipes for hair-cell regeneration? Neuron 19: 951-4.

DIAZ, M.E., VARELA, A. AND SERRANO, E.E. (1995). Quantity, bundle types and distribution of hair cells in the sacculus of Xenopus laevis during development. Hear. Res. 91: 33-42.

FRITZ A., GORLICK D.L. AND BURD G.D. (1996). Neurogenesis in the olfactory bulb of the frog Xenopus laevis shows unique patterns during embryonic development and metamorphosis. Int. J. Dev. Neurosci. 14: 931-943.

GALLAGHER B., HENRY J. AND GRAINGER R. (1996). Inductive processes leading to inner ear formation during Xenopus development. Dev. Biol.175: 95-
107.

GOODYEAR R.J. AND RICHARDSON G.P. (1997). Pattern formation in the basilar papilla: evidence for cell rearrangement. J. Neurosci.17:6289-6301.

GRATZNER H.G. (1982). Monoclonal antibody to 5-bromo- and 5-iododeoxyuridine: A new reagent for detection of DNA replication. Science 218:474-5

HADDON C AND LEWIS J. (1991). Hyaluronan as a propellant for epithelial movement: the development of semicircular canals in the inner ear of Xenopus. Development 112: 541-550.

HARRIS, J.A., CHENG, A.G., CUNNINGHAM, L.L., MACDONALD, G., RAIBLE D.W. AND RUBEL, EW. (2003). Neomycin-induced hair cell death and rapid regeneration in the lateral line of zebrafish (Danio rerio). J. Assoc. Res. Otolaryngol. 4: 219-34.

HENSEY, C. and GAUTIER, G. (1998). Programmed cell death during Xenopus development: A spatio-temporal analysis. Dev. Biol. 203:36-48.

KAY B.K. AND PENG H.B. (1991). Xenopus laevis: Practical uses in cell and molecular biology. Methods in Cell Biology. Academic Press, San Diego.

KELLEY, M.W., OCHIAI, C.O. AND CORWIN, J.T. (1992). Maturation of kinocilia in amphibian hair cells: Growth and shortening related to kinociliary bulb formation. Hear. Res. 59: 108-115.

KIL, S.H. and COLLAZO, A. (2001). Origins of inner ear sensory organs revealed by fate map and time lapse analyses. Dev. Biol. 233: 365-379.

KIMMEL, C.B., MILLER, C.T., KRUZE, G., ULLMAN, B., BREMILLER, R.A. LARISON, K.D. AND SNYDER, H.C. (1998). The shaping of pharyngea cartilages during early development of the zebrafish. Dev. Biol. 203: 245-263.

KOLB B., PEDERSEN B., BALLERMANN M., GIBB R. AND WHISHAW I.Q. (1999). Embryonic and postnatal injections of bromodeoxyuridine produce age-dependent morphological and behavioral abnormalities. J. Neurosci. 19: 2337-2346

LANG, H., BEVER, M.M. AND FEKETE, D.M. (2000). Cell proliferation and cell death in the developing chick inner ear: spatial and temporal patterns. J. Comp. Neurol. 417: 205-220.

LI C.W. AND LEWIS E.R. (1979). Structure and development of vestibular hair cells in the larval bullfrog. Ann. Otol. Rhinol. Laryngol. 88:427-37.

LOMBARTE, A., YAN, H.Y., POPPER, A.N., CHANG, J.S. AND PLATT, C. (1993). Damage and regeneration of hair cell ciliary bundles in a fish ear following treatment with gentamicin. Hear. Res. 64: 166-74.

MATSUI J.I., PARKER M.A., RYALS B.M. AND COTANCHE, D.A. (2005). Regeneration and replacement in the vertebrate inner ear. Drug Discov. Today 10 1307-12.

MATSUI J.I. and RYALS B.M. (2005) Hair cell regeneration: An exciting phenomenon... But will restoring hearing and balance be possible? J. Rehabil. Res. Dev. 42:187-98.

MCDIARMID RW AND ALTIG R. (1999). Research: materials and techniques. In Tadpoles: the biology of anuran larvae, (Eds. McDiarmid R.W. and Altig R.), pp. 7-23, University of Chicago Press, Chicago.

MILLER M.W. AND NOWAKOWSKI R.S. (1988). Use of bromodeoxyuridine immunohistochemistry to examine the proliferation, migration and time of origin of cells in the central nervous system. Brain Res. 457: 44-52.

MITCHELL, R.E. (2006). How many deaf people are there in the United States? Estimates from the survey of income and program participation. J. Deaf Stud. Deaf. Educ. 11: 112-9.

NIEUWKOOP, P. AND FABER, J. (1967). Normal table of Xenopus laevis (Daudin): A systematical and chronological survey of the development from the fertilized egg till the end of metamorphosis. $2^{\text {nd }}$ Edition, North Holland, Pub., Amsterdam.

NORAMLY S. and GRAINGER R.M. (2002). Determination of the embryonic inner ear. JNeurobiol. 53: 100-128.

OKANO J., TAKIGAWA T., SEKI K., SUZUKI S., SHIOTA K. AND ISHIBASHI, M. (2005). Transforming growth factor beta 2 promotes the formation of the mouse cochleovestibular ganglion in organ culture. Int. J. Dev. Biol. 49: 23-31.

PATERSON N.L. (1948). The development of the inner ear of Xenopus laevis. Proc. Zool. Soc. Lond.119: 269-291.

PELLICER M., GIRALDEZ F., PUMAROLA F. AND BARQUINERO J. (2005) Stem cells for the treatment of hearing loss. Acta Otorrinolaringol Esp. 56: 227-32.

PETIT C. (2006) From deafness genes to hearing mechanisms: harmony and counterpoint. Trends Mol. Med. 12: 57-64. 
PIZARRO I.V., SWAIN G.P. AND SELZER M.E. (2004). Cell proliferation in the lamprey central nervous system. J. Comp. Neurol. 469: 298-310.

QUICK Q.A. and SERRANO E.E. (2005). Inner ear formation during the early larval development of Xenopus laevis. Dev. Dyn. 234: 791-801.

REPRESA J. and BERND P. (1989). Nerve growth factor and serum differentially regulate development of the embryonic otic vesicle and cochleovestibular ganglion in vitro. Dev. Biol. 134: 21-9.

SCHLOSSER G., KOYANO-NAKAGAWA N. AND KINTNER C. (2002). Thyroid hormone promotes neurogenesis in the Xenopus spinal cord. Dev. Dyn. 225: 485-498.

SERRANO EE, TRUJILLO-PROVENCIO C, SULTEMEIER DR, BULLOCK WM AND QUICK QA. (2001). Identification of genes expressed in the Xenopusinner ear. Cell. Mol. Biol. (Noisy-le-grand) 47:1229-39.

STOCKDALE F., OKAZAKI K., NAMEROFF M. AND HOLTZER H. (1964). 5Bromodeoxyuridine: Effect on myogenesis in vitro. Science 146: 533-5.

STONE, J. and COTANCHE, D. (1994). Identification of the timing of S phase and the patterns of cell proliferation during hair cell regeneration in the cochlea. $J$. Comp. Neurol. 341: 50-67.

TAYLOR, R.R. and FORGE, A. (2005). Hair cell regeneration in sensory epithelia from the inner ear of a urodele amphibian. J. Comp. Neurol. 484: 105-20.

TORRES, M. AND GIRALDEZ, F. (1998). The development of the vertebrate inner ear. Mech. Dev. 71: 5-21.

WALSH, R.M., HACKNEY, C.M. AND FURNESS, D.N. (2000). Regeneration of the mammalian vestibular sensory epithelium following gentamicin-induced damage. J. Otolaryngol. 29: 351-60.

WILKINS, H.R., PRESSON, J.C. AND POPPER, A.N. (1999). Proliferation of vertebrate inner ear supporting cells. J. Neurobiol. 39: 527-535.

ZHENG, J.L. and GAO, W. (1997). Analysis of rat vestibular hair cell development and regeneration using calretinin as an early marker. J. Neurosci. 21: 82708282.

Received: 9th May 2006

Reviewed by Referees: 7th August 2006

Modified by Authors and Accepted for Publication: 15th December 2006

Published Online: 7th March 2007

\section{Related Int. J. Dev. Biol. articles}

See our forthcoming Special Issue on Ear Developmentedited by F. Giraldez and B. Fritzsch, due in June 2007 at: http:/ /www.intjdevbiol.com

Proliferation and apoptosis in early molar morphogenesis - voles as models in odontogenesis. Jana Setkova, Herve Lesot, Eva Matalova, Kirsti Witter, Petra Matulova and Ivan Misek. Int. J. Dev. Biol. (2006) 50: 481-489.

Transforming growth factor beta2 promotes the formation of the mouse cochleovestibular ganglion in organ culture. Junko Okano, Toshiya Takigawa, Kenji Seki, Shigehiko Suzuki, Kohei Shiota and Makoto Ishibashi. Int. J. Dev. Biol. (2005) 49: 23-31.

Functional analysis of FGF3 during zebrafish inner ear development. $V$ Vendrell, D Gimnopoulos, T Becker, $T$ Schimmang. Int. J. Dev. Biol. (2001) 45: S105-S106.

The cytoskeletal effector XPAK1 is expressed during both ear and lateral line development in Xenopus. N/slam, L Poitras and T Moss. Int. J. Dev. Biol. (2000) 44: 245-248.

Differential expression of microtubule associated protein MAP-2 in developing cochleovestibular neurons and its modulation by neurotrophin-3. I San José, E Vázquez, N García-Atares, J J Huerta, J A Vega and J Represa. Int. J. Dev. Biol. (1997) 41: 509-519.

Distribution of BDNF and trkB mRNA in the otic region of 3.5 and 4.5 day chick embryos as revealed with a combination of in situ hybridization and tract tracing. F Hallböök and B Fritzsch. Int. J. Dev. Biol. (1997) 41: 725-732.

How does the urodele ear develop? B Fritzsch. Int. J. Dev. Biol. (1996) 40: 763-771.

Co-culture of contiguous developmental fields in a serumless, chemically-defined medium: an in vitro model permissive for coordinate development of the mouse ear. D S Hoffman, P Bringas and H C Slavkin. Int. J. Dev. Biol. (1996) 40: 953964. 